\title{
ПСИХОЛОГИЧЕСКИЕ АСПЕКТЫ ПОДРОСТКОВЫХ
} КОНФЛИКТОВ

\section{PSYCHOLOGICAL ASPECTS OF ADOLESCENT CONFLICTS}

\section{N. Larionova}

Summary: The article actualizes the problem of determining the main psychological aspects of the emergence of conflict situations with the participation of adolescents. The author notes that at present, the issues of regulating interpersonal relations in groups of adolescents and the formation of relationships between teachers, students, parents, seem to be necessary to increase the effectiveness of the educational process. The article also notes that a modern teenager is deprived of the opportunity to understand the essence of the conflict, to see its origins, content, course of development, consequences, possible ways to resolve and prevent conflict, to gain experience of rational behavior in a conflict, which justifies the advisability of constructive help from adults, in the first place queue - teachers and parents.

Keywords: conflict, adolescents, psychological aspects, character, personality.

\author{
Ларионова Надежда Александровна \\ Д.nсх.н., профессор, Российский государственный \\ сочиальный университет \\ pslogos@mail.ru
}

Аннотация: В статье актуализируется проблема определения основных психологических аспектов возникновения конфликтных ситуаций с участием личностей подросткового возраста. Автором отмечено, что в настоящее время вопросы регуляции межличностных отношений в коллективах подростков и формирования взаимоотношений между учителями, учениками, родителями, представляются необходимыми для повышения эффективности учебно-воспитательного процесса. Также в статье отмечено, что современный подросток лишен возможности понять сущность конфликта, увидеть его истоки, содержание, ход развития, последствия, возможные способы решения и предотвращения конфликта, приобрести опыт рационального поведения в конфликте, что обосновывает целесообразность конструктивной помощи со стороны взрослых, в первую очередь - педагогов и родителей.

Ключевые слова: конфликт, подростки, психологические аспекты, характер, личность.

начала становления личностного «Я» индивида. Кроме того, с точки зрения биологии и физиологии, это период завершения физического созревания.

Развитие личности в подростковом возрасте сопровождается возникновением внутриличностных противоречий. Подростку характерно проявление противоречий между рядом личностных интересов и желаний, с одной стороны, и ограниченностью сил, опыта, возможностей для их реализации с другой [3]. Наличие таких противоречий, их возникновение, развитие и решение оказывают существенное влияние на личность подростка. Наличие нерешенных внутриличностных противоречий ведет к отклонению в поведении, процесс решения этих противоречий приобретает затяжную конфликтную форму. Следовательно, основные объективные противоречия подросткового возраста и порождают его конфликтность.

Сорокина Г.А. и Сафонова М.В. в своих наработках отмечают, что в начале подросткового периода складывается ситуация, которая способствует возникновению противоречий при условии сохранения отношения взрослых к подростку как к ребенку [6]. Это отношение, с одной стороны, входит в противоречие с задачами воспитания и тормозит развитие социальной взрослости подростка, с другой - не соответствует представлени- 
ям подростка о степени собственной взрослости и его претензиям на новые права. Именно это противоречие является источником большинства конфликтов и трудностей в отношениях подростка со взрослыми, сверстниками, родителями.

Повышенная конфликтность подросткового возраста обусловлена тем, что в 12-14 лет в психологическом развитии многих детей наступает переломный момент, известный под названием «подросткового кризиса». Существование противоположных тенденций порождают столкновения, которые при неизменности отношения взрослого становятся систематическими, а негативизм подростка - усиливается. При условии сохранения ситуации, изменение предыдущих отношений может затянуться на весь подростковый период и принять форму хронического конфликта. Как правило, сначала это конфликты поступков, только потом - конфликты отношений. Конфликт может продолжаться до тех пор, пока взрослый не изменит своего отношения к подростку. Только при таких условиях появляется возможность создать эффективное межличностное общение взрослых и детей.

Конфликты занимают существенное место в повседневной жизни, поскольку они являются важной детерминантой человеческой активности и находятся в поле исследований психологов. Психологические традиции изучения этого сложного явления имеют истоки в психоаналитической и социологической школах, которые содержат внушительный арсенал методов распознавания, описания и исследования конфликтов. Понятие «конфликт» используется почти во всех общественных науках и в каждой из них является одной из ведущих категорий. Сам термин «конфликт» (от лат. confliktus - столкновение) не интерпретируется исследователями однозначно. В психологии под конфликтом понимается столкновение противоположно направленных, несовместимых между собой тенденций в сознании отдельно взятого индивида, в межличностных отношениях индивидов или групп людей, связанное с острыми отрицательными эмоциональными переживаниями [1].

Конфликты изучаются в рамках общепсихологических параметров межличностных конфликтов. Многие исследования посвящены изучению психологических детерминант конфликтного поведения, способов его психологической коррекции и соответствующих черт личности, типологии конфликтов, закономерностей их возникновения. В психолого-педагогических исследованиях основное внимание уделяется изучению школьных конфликтов. Так, отечественные исследователи Ковальчук И.А. и Москвина Ю.М. считают, что предупреждение и разрешение конфликтных ситуаций в среде подростков во многом зависит от личностных особенностей педагога: профессионализма, педагогического такта и др.[4].
Реан А.А. отмечает, что конфликты среди подростков представляются закономерным явлением, но, осознавая возможность неприятных последствий конфликтов в виде разного рода психических травм, одновременно конфликты автором определяются неизбежным условием развития личности ребенка [5]. При этом, в конфликте заложены большие положительные функции, которые могут выполнять конструктивную роль в воспитании.

На деструктивных последствиях конфликтов акцентируют внимание Чикова И.В. и Мантрова М.С., констатируя в своих исследованиях, что в процессе конфликтного взаимодействия каждая из сторон планирует и осуществляет такое действие, которое наносит вред оппоненту (второй стороне конфликта) [9]. В ряде исследований рассмотрены психологические аспекты конфликтов в контексте проблем возрастного кризиса, школьной дезадаптации и стереотипов поведения ребенка, сформированных в процессе семейного воспитания.

В целом, в психологии понятие возрастных кризисов ассоциируется с состоянием выраженной конфликтности. Личностным фактором возникновения конфликтов является уровень конфликтности индивида. Когда этот уровень высок, говорят о «конфликтности» субъекта, который подвержен конфликтным взаимоотношениям. Обобщая исследования в сфере современной подростковой психологии, можно сказать, что конфликтность является системным сложным свойством личности, включающим комплекс психических свойств, а именно:

- неадекватную (завышенную или заниженную) самооценку своих возможностей и способностей, которая идет в разрез с оценками окружающих, что и вызывает конфликт;

- стремление доминировать в тех ситуациях, где это возможно и невозможно;

- статичность мышления, взглядов, убеждений, нежелание воспринимать факты, которые расходятся с субъективным мнением;

- излишняя принципиальность и прямолинейность в высказываниях и суждениях, стремление сказать то, что является, по мнению личности, правдой, нивелируя объективность;

- определенный набор эмоциональных качеств подростка: тревожность, агрессивность, упрямство, раздражительность.

Представители ситуационного подхода к конфликтам дают свою интерпретацию определения конфликтности. Туницин А.В. конфликтной личностью называет человека, который является участником конфликтных взаимодействий, то есть имеет повышенную склонность к восприятию ситуаций как конфликтных или определяет его как склонного к конфликтному реагированию на те или иные обстоятельства [7]. По мнению Джиоевой О.Ф. и Султановой К.А., конфликтность может быть характе- 
ристикой «невротической личности», когда субъект невротично реагирует на жизненные ситуации, которые у здорового человека не вызывают конфликта вообще [2].

Таким образом, конфликтность в психологии определяется преимущественно как перманентная черта личности, которая аккумулируется ее природными задатками и социальным опытом. Конфликтность подростка предполагает определенный уровень психической напряженности. Он может быть разным для разных субъектов, что связано с уровнем психологической устойчивости человека. Психически устойчивые и психически неустойчивые люди в сложных ситуациях ведут себя по-разному. У перманентно психически неустойчивых подростков (в силу возрастных изменений личнсоти) отсутствуют эффективные способы преодоления препятствий, поэтому иногда наблюдается явление самоиндукции отрицательного эмоционального напряжения: дезорганизованное поведение усиливает стрессовое состояние и продуцирует возникновение «волны дезорганизации» [5].

Конфликтность личности подростка определяется следующим комплексом факторов:

- психологических: темперамент, уровень агрессивности, эмоциональное состояние (тревожность) и т.д.;

- социально-психологических: социальные установки и ценности, отношение к оппоненту, направленность во взаимодействии, компетентность в общении, интеллект, основные тенденции поведения;

- социальных факторов: условия жизни и деятельности, возможности релаксации, социальное окружение, общий уровень культуры, возможности для удовлетворения потребностей и т.д.

Конфликтность среди подростков носит остро выраженный характер, что ведет к росту хулиганства, краж, преступлений, правонарушений среди несовершеннолетних. Любое противоречие, которое может ограничить права подрастающей личности, сразу вызывает у нее реакцию протеста, эмоциональный срыв. Склонность к конфликтности у подростков в учебно-воспитательном процессе является важной проблемой социально-психологического характера. Правильное управление процессом решения конфликта или его предупреждение взрослыми или самим подростком способствует повышению эффективности общения. В условиях образовательных учреждений важным фактором преодоления негативных проявлений конфликта среди подростков является понимание педагогом личности учащегося, что способствует гармоничному развитию субъектов коммуникаций и взаимодействия.

Конфликтность подростков отличается рядом осо- бенностей, связанных с недостаточностью жизненного опыта и низким уровнем самокритики, неспособностью к адекватной оценке жизненных обстоятельств, повышенной эмоциональной возбудимостью, импульсивностью, двигательной и вербальной активностью, обостренным чувством зависимости, стремлением к обретению определенного статуса в референтной группе, негативизмом, неуравновешенностью возбуждения и торможения.

Подростковая склонность к конфликтности может объясняться не только эмоциональными и физиологическими возрастными изменениями. Одной из характеристик неустойчивого, дискомфортного положения подростка является недостаточная сформированность его социальных навыков, способствующих успешной социализации. Недостаточно сформированные социальные навыки, усиленные социально-экономической незащищенностью, часто является причиной, которая влияет на повышенную агрессивность, конфликтность подростка, на его желание любыми средствами компенсировать свое недовольство жизнью.

Подростки сталкиваются с целым рядом противоречивых позиций и внутренних колебаний между зависимостью и независимостью, ролью ребенка и взрослого. Молодой человек, перед которым стоит задача смены ролей, довольно часто оказывается в ситуации ролевых конфликтов. Проблемы противоречий, касающихся деятельностной сферы личности, могут переживаться как ролевые конфликты. В подростковом возрасте требования социальной среды (родителей, учителей, сверстников) могут оказаться взаимопротиворечащими. Смена ролей, необходимость принятия важных решений относительно ценностных ориентаций могут вызвать ролевой конфликт и статусную неопределенность, что также накладывает явный отпечаток на концепцию личностного «Я» $[8]$.

Переход от нормальных потребностей личности к нарушению социальных норм возможен только при конфликтной ситуации объективного или субъективного характера. Контрастность детства и зрелости, между которыми находится подросток, усложняет усвоение социальных ролей и порождает немало внешних и внутренних конфликтов. Кроме того, существует проблема индивидуальных различий. Общие закономерности проявляют себя через индивидуальные вариации, которые зависят не только от окружающей подростка среды и условий воспитания, но и от особенностей личности [1]. Важная особенность поведения подростков - это долговременные конфликтные отношения с окружающими. Когда поведение подростка вызывает возмущение окружающих, они реагируют на их действия острыми критическими замечаниями, наказаниями, негативным отношением, подросток это расценивает как враждебные действия, как покушение на его независимость, самосто- 
ятельность, личное достоинство.

В частности, конфликты подростков и родителей обусловлены деструктивностью внутрисемейных отношений, недостатками в воспитании, индивидуально-психологическими изменениями в психическом развитии подростков и индивидуальными особенностями самих взрослых. Конфликтное поведение подростков возникает тогда, когда не учитываются индивидуальные особенности, возрастные изменения в психике, когда не меняется форма и содержание общения взрослых [5]. Конфликтные отношения способствуют развитию приспособительных форм поведения и эмансипации подростка. Появляются отчужденность, убеждение в несправедливости, что далее продуцирует сознательное неприятие требований, оценок, взглядов взрослого, который в подобной ситуации с позиций подростка может потерять уважение, влияние в ответственный период формирования личности [3].

В подростковом возрасте увеличивается количество сложных педагогических ситуаций, которые усиливают конфликтность подростка, при этом следует констатировать, что трудности коммуникации возникают не только у детей, но и у взрослых. Часто взрослые оказываются не готовыми к тому, чтобы расширить права подростков по причине сохранения инерции «опекать». В данном случае сохраняется зависимость детей от родителей и их неспособность к самостоятельным действиям и принятию решений [9].

Подростки часто конфликтуют между собой в связи с различными статусами, которые они занимают в межличностных отношениях. Это, как правило, затяжные, долгие конфликты, причины которых скрыты от учителей и родителей, а, следовательно, их трудно решать. Часть конфликтов, которые наблюдаются, является следствием противоречий, которые возникают между высокой самооценкой и не соответствующим ей реальным положением подростка в коллективе сверстников. Личность с уровнем зрелости подростка в конфликте выражает «внешний локус контроля», обвиняя других людей или какие-то обстоятельства. Подросток не верит в свои силы в решении конфликтной ситуации, занимая пассивную поведенческую позицию и чувствуя астенические эмоции, но при этом стремится к достижению субъектно-личностного результата показать себя, почувствовать уверенность в своих силах [6].

Таким образом, ключевыми психологическими аспектами конфликтного поведения подростков является эгоизм, упрямство, желание «поддержать компанию», противоречия общих и личных интересов, несогласие с мнением других, трудности общения с учителями и родителями. В указанные аспекты продуцируют объективные причины для конфликтов в сложной системе взаимоотношений. Следовательно, можно предположить, что общение, учебная, трудовая и любая другая деятельность сама по себе может стать источником внутриличностного конфликта, если цели и задачи этой деятельности характеризуются выраженной субъективной значимостью. В подростковом возрасте особую ценность приобретает общение. Именно неуспеваемость в этом виде деятельности чаще всего вызывает внутриличностные конфликты, решить которые можно с помощью обучения подростков навыкам конструктивного, толерантного общения.

\section{ЛИТЕРАТУРА}

1. Гришина Н.В. Психология конфликта. 2-е изд. СПб.: Питер, 2008. 544 с.

2. Джиоева 0.Ф., Султанова К.А. Психологические барьеры общения в подростковом возрасте // Азимут научных исследований: педагогика и психология. 2016. T. 5. № 4 (17). С. 115-117.

3. Ильин Е.П. Психология общения и межличностных отношений. СПб.: Питер, 2010.576 с.

4. Ковальчук И.А., Москвина Ю.М. Агрессивное поведение: биологические и социальные аспекты // Novalnfo. 2016. Т. 3. № 48. С. $453-456$.

5. Реан А.А. Психология личности. СПб.: Питер, 2013. 288 с.

6. Сорокина Г.А., Сафонова М.В. Особенности протекания внутриличностных конфликтов старшеклассников // Молодой ученый. 2016. № 20 (124). C. 657-659.

7. Туницин А.В. Взаимосвязь стратегии разрешения конфликтов и межличностных отношений в юношеском возрасте // Методист. 2020. № 5. С. 34-35.

8. Халилов Б.Б. Влияние конфликтного поведения подростка на положение в группе сверстников // Novalnfo. 2016. Т. 1. № 48. С. $323-327$.

9. Чикова И.В., Мантрова М.С. Психологические особенности конфликтности современных подростков // Азимут научных исследований: педагогика и психология. 2019. Т. 8. № 4 (29). С. 386-389.

(c) Ларионова Надежда Александровна (pslogos@mail.ru). 